\title{
INTERVENÇÕES EDUCACIONAIS E SUBJETIVIDADE: O DESAFIO DA AÇÃO CONCRETA EM INVESTIGAÇÕES CIENTÍFICAS
}

\author{
EDUCATIONAL INTERVENTION AND SUBJECTIVITY: THE CHALLENGE OF \\ OBJECTIVE ACTION IN SCIENTIFIC INVESTIGATIONS
}

\author{
D Leila Maria Vieira Kim \\ Doutorado em Psicologia \\ Universidade de São Paulo - USP \\ São Paulo, SP. - Brasil. \\ leilakim.animus@gmail.com \\ Elaine Teresinha Dal Mas Dias \\ Doutorado em Psicologia \\ Universidade de São Paulo - USP \\ São Paulo, SP. - Brasil. \\ elaine.mas@uni9.pro.br
}

\begin{abstract}
Resumo: Este artigo mapeia o lugar ocupado pelas intervenções educacionais no conhecimento científico na contemporaneidade. O objetivo é democratizar informações básicas sobre intervenção social, para nela incluir novos pesquisadores que atuam na área educacional. Para isso, sintetizamos questões teóricas e práticas que permeiam a construção do conhecimento em ciências de fronteira e de vanguarda, bem como a ruptura causada pelas intervenções, enquanto ciência aplicada na área socioeducacional. Consideramos a importância desta técnica científica de pesquisa em situações de turbulência decorrentes de crises, que demandam soluções mais adequadas ao momento sociocultural, econômico e político em que vivemos. Exemplificamos sua aplicação em projetos de pesquisa-ação instrumentalizados pelo psicodrama pedagógico articulado à psicanálise, em programas participativos da sociedade civil e do Estado; na interrelação professor-aluno para a aquisição da leitura e escrita; em grupo de idosos e em sala de aula de curso de pós-graduação, em uma universidade portuguesa.
\end{abstract}

Palavras-chave: Ciência. Intervenção educacional. Pesquisa-ação. Cultura.

\begin{abstract}
This article indicates the place occupied by educational interventions in scientific knowledge nowadays. We intend to share fundamental information about social intervention with it, so there may be possible to include new researchers who work in educational area. This way, we summarized theoretical and practical issues that are part of the knowledge construction in frontier and vanguard science, as well as the rupture resulted from interventions, as Applied Science in socioeducational area. We consider the importance of this scientific research technique in disturbance situations, resultant from crisis that demand solutions more adequate to the sociocultural, economic and political moment we are living in. We exemplified their application in action research projects, structured by pedagogical psychodrama, associated to psychoanalysis in participative programs from civil Society and Government; in interrelationship between the teacher and the student in literacy process; in an elderly group and in postgraduation course classes, at a University in Portugal.
\end{abstract}

Keywords: Science. Educational intervention. Action research. Culture.

Para citar - (ABNT NBR 6023:2018)

KIM, Leila Maria Vieira; DIAS, Elaine Teresinha Dal Mas. Intervenções educacionais e subjetividade: o desafio da ação concreta em investigações científicas. Eccos - Revista Científica, São Paulo, n. 56, p. 1-17, e8585, jan./mar. 2021. Disponível em: https://doi.org/10.5585/eccos.n56.8585. 


\section{Introdução}

O presente artigo nasceu da pré-ocupação em articular o conhecimento, adquirido durante toda a nossa formação acadêmica, sobre a pesquisa científica aplicada nas práticas sociais, por meio de intervenções educacionais com base psicanalítica. O acontecimento decisivo que nos levou à presente escrita foi voltar a ser estudante e contar com a supervisão de duas professoras em cursos de pós-doutorado em universidades de Portugal e do Brasil. Nestes cursos pudemos apreender, sob a lógica da curiosidade, conteúdos publicados por autores como Baptista (2006, 2013), Bion (1966, 1969, 1987), Foucault (1979), Morin (1973, 2003, 2015) e Severino (2005), que diminuíram as limitações de nossos conhecimentos e nos permitiram a iniciação em um olhar transcultural. As investigações (KIM, 2008, 2016, 2017; KIM; DIAS, 2017) de onde derivou o método que articula a técnica científica do psicodrama ao pensar psicanalítico em intervenções educacionais grupais com professores e idosos, sob a perspectiva do ócio criativo ${ }^{1}$, alimentaram nossas interrogações iniciais e nos lançaram em trocas com colegas que frequentam aquelas universidades. Deste modo, a partir de nossa própria experiência constatamos as dificuldades inerentes ao nascimento de "uma nova concepção da ciência, que conteste e perturbe, não só as fronteiras estabelecidas, mas também as pedras angulares dos paradigmas. E, em certa medida, a própria instituição científica ${ }^{2}$ " (MORIN, 1973, p. 208). Em outras palavras, partimos do pressuposto de que a proposta de pesquisa em ciências de vanguarda ${ }^{3}$ provocou uma dupla ruptura na tradição da forma como se chega à verdade (método) da ciência especulativa, ao considerar que:

1) não há uma relação de continuidade entre o conhecimento e as coisas a se conhecer, pois as condições do objeto da experiência são heterogêneas e não idênticas;

2) O sujeito humano não é uno e soberano sobre as "coisas" e "objetos" (KAUFFMANN, 2008) a serem pesquisados.

Desse modo, a intervenção social vem-se institucionalizando como um caso particular de técnica científica,

\footnotetext{
${ }^{1}$ Segundo Csikszentmihalyi (2001 apud CABEZA; AMIGO, 2014), "no mundo das ideias, o ócio permite à mente desligar-se temporariamente da realidade tal como a contemplamos, para que emerjam novas possibilidades que serão posteriormente transformadas em realidade"; ele possibilita o "não pensado", a existência de um outro nível de conhecimento, que deixa vir até si a verdade (BAPTISTA, 2013,p. 178).

Método intelectual de crítica, que conjuga razão (legitimidade lógica) e experiência na constituição do conhecimento (KIM, 2009, p. 26).

${ }^{3}$ Nas ciências de vanguarda, conhecer é analisar/interpretar post hoc os dados obtidos na realidade pesquisada, fundamentando-se em subsídios teóricos (KIM, 2009, p. 28).
} 
[...] visto que desenvolveu um conjunto de procedimentos ótimos para um fim prático. Constituiu-se como um projeto estratégico na direção da solução de problemas da realidade social e política [...]. Nela há uma mudança na representação do tempo: interfere no tempo invariante, no decorrer do qual o objeto de estudo se transforma. Com isso, a intervenção social garante um estatuto epistemológico equivalente ao movimento intrínseco deste objeto. [...] é considerada pesquisa, quando ela gera conhecimento sobre o problema da realidade social, e não sobre a questão técnica em si. (KIM, 2009, p. 26, grifo da autora)

A consciência crítica está na base da implementação do plano de ações da intervenção social, porque a problemática - ideologia que cria e mantém o problema - tem de ser identificada e analisada. Segundo Morin (2015, p. 13, grifo nosso), “a estratégia política requer o conhecimento complexo, porque ela se constrói na ação [...] no acaso, no jogo múltiplo de interações e retroações". Na medida em que os cenários da ação se modificam, surgem novos desafios nos quais iniciativa, capacidade de decisão e inibição da ação impulsiva possibilitam o pensar estratégico dos sujeitos participantes, de acordo com "as informações que vão chegar no curso da ação e segundo os acasos que vão se suceder e perturbar a ação" (MORIN, 2015, p. 79). Então, na intervenção socioeducacional, a especulação, enquanto instrumento e não como objetivo, fundamenta teoricamente o que se observa, o que se acrescenta e se modifica nas práticas sociais. Nela,

[...] o pesquisador só consegue desenhar um recorte no momento histórico contemporâneo em processo de construção, se ele visualiza a si mesmo neste contexto [...] adaptando-se às forças que o pressionam e o conduzem à situação de produtor-consumidor, aprisionado em uma complexa rede de objetos de desejo. (KIM, 2008, p. 44)

Segundo Severino (2005, p. 37), “é mediante o exercício de sua subjetividade que os homens podem intencionalizar sua prática, atribuindo-lhe uma significação conceitual e valorativa". Assim sendo, o lugar do conhecimento advindo das práticas sociais - produzido, sistematizado e disseminado pelos processos educativos, apoiado pelo Estado e espraiado pela sociedade civil - deveria ocupar lugar fundamental na contemporaneidade. Todavia, o poder do conhecimento foi sequestrado pelo poder político, que por sua vez tem sido confiscado pelo poder econômico. Dessa forma, o comprometimento ideológico da instituição ciência com o pensamento hegemônico do mercantilismo neocapitalista tem garantido a manutenção do status quo e desafiado a subjetividade. Urge a constituição de movimentos de resistência política, por meio da explicitação da universalidade dos valores culturais e da análise crítica dos vários discursos pedagógicos que permeiam nosso imaginário social, por meio da coconstrução coletiva do conhecimento, pois somente assim a educação poderá “cumprir esse papel emancipatório exercendo-se como mediação efetiva dos resultados do conhecimento, 
para a significação e orientação da prática humana responsável pela configuração da própria existência dos homens" (SEVERINO, 2005, p. 38).

Percebemos que, na contemporaneidade, as políticas públicas educacionais aplicadas no ambiente ${ }^{4}$ cultural têm-se caracterizado como uma paisagem ${ }^{5}$, que representa um conjunto difuso. A reivindicação de intervenções educacionais ${ }^{6}$ com diferentes atores sociais poderia, no imaginário grupal, fragmentar a paisagem para reconstituir os fios da rede que ligam os diferentes elementos constituintes desta paisagem. Em nossa leitura de Foucault (1979), tal reivindicação significaria um primeiro passo para se criarem resistências: sinais de luta contra a repressão. Pois, enquanto intervenção concreta, ela atingiria seu alvo principal - a população representada pelos sujeitos participantes - e seus dispositivos de segurança, que recobrem um conjunto heterogêneo em conformidade consigo mesmo. Desta forma, enquanto pesquisa-ação ${ }^{7}$, possibilitaria um "espaço de locução" "8 no qual se desvelaria o vazio existente entre as relações desiguais de forças estabilizadas de poder, que se manifestariam como acontecimentos no "teatro dos procedimentos" (FOUCAULT, 1979, p. 17).

Assim fundamentadas, supomos que a intervenção grupal pode constituir-se como um instrumento capaz de propiciar movimentos de resistência frente às infraestruturas, na medida em que permite a cada um dos participantes do grupo a evolução de sua capacidade de pensar o próprio pensamento (BION, 1966) e de se relacionar com os outros sujeitos inseridos no processo de co-construção coletiva do conhecimento.

A crise social vivida na contemporaneidade impõe a criação de métodos de intervenção adequados à realidade cultural. Para Anzieu (1972, p. 62-63, 65),

[...] necessitamos de marcos teóricos e estratégias para pensar, tratar e utilizar as crises [...] pois pela crise o homem se cria homem e sua história transita entre crise e resolução. [Portanto,] a criação é a alternativa da vida frente aos componentes letais da crise [...] É importante criar dispositivos aptos para superá-la e conceitos adequados para pensá-la.

A ruptura e a separação características da crise denotam o momento de criação de uma nova categoria. Nesta perspectiva, propomos no presente artigo o desenvolvimento de uma visão de ciência aplicada, onde cultura, técnica e ambiente tendem a se tornar inseparáveis.

\footnotetext{
${ }^{4}$ Ambiente: é a organização humana no espaço total, de tal forma que é sempre socioambiente (SANTOS, 2004), porque nele, sujeito e objeto coexistem enquanto produção social, cultural e política.

Paisagem: região geocultural claramente definida com capacidade de ilustrar elementos culturais distintos dessa região, incluindo ideias de pertencimento, significado, valor e singularidade do lugar (RIBEIRO, 2007).

${ }^{6}$ Intervenção educacional: "Estratégia de ação social que, exercendo funções pedagógicas, aumentaria o alcance histórico e o significado social de suas repercussões imediatas, e, por meio da crítica política de seu desempenho, conduziria a um maior entendimento da estrutura social" (TASSARA, 1982, p. 7). 7 "Pesquisa-ação é um método científico que possibilita a participação igualitária entre pesquisador e participantes, de modo que todos são sujeito e objeto do estudo. Nela se coletam os dados referentes aos problemas do ambiente local, que podem ser derivados para a percepção da problemática/ideologia subjacente" (KIM, 2017, p. 7). "O conhecimento produzido resulta de um cotejamento entre a sabedoria popular dos usuários e o consenso dos pesquisadores sobre o que está sendo observado e interpretado." (KIM, 2009, p. 30)

${ }^{8}$ Habermas $(1994$, p. 88 ) propôs a intervenção social como uma possibilidade utópica de se criarem "espaços de locução" em diferentes instâncias, tendo o Estado como coparticipante, para a organização da temporalidade dos cidadãos em dimensões de maior profundidade e autenticidade.
} 


\section{A intervenção educacional}

A prática da intervenção educacional por ação estratégica constitui-se como um plano de ação social cujo objetivo é possibilitar a "construção de um caminho utópico na direção de um aprimoramento das formas de convívio social pari passu com a transformação psicossocial dos sujeitos nela envolvidos, via intervenções educativas e democráticas" (TASSARA, 1982, p. 7). Esta prática vem-se institucionalizando como um conjunto de prescrições relativas ao desenvolvimento de atividades, em escolas e outras instituições, organizações governamentais e empresariais, assim como em diferentes espaços de locução. Ela se tem constituído como "técnica científica: instrumental sócio educacional que sistematiza o conhecimento teórico pela análise interpretativa das produções obtidas nas práticas” (KIM, 2009, p. 28). Todavia, consideramos a necessidade da democratização destas produções por meio de informações disponíveis como ação estratégica de rede, para que a intervenção educacional possa constituir-se como uma alternativa de escolha para a inclusão de outros pesquisadores que atuam na área educacional, pois é preciso transformar as produções de pesquisa em linguagens que ampliem o número de interlocutores da ciência.

Para Morin (2003), as instituições escolares fornecem o modelo de fragmentação do conhecimento desde a pré-escola até a universidade; com isso, consideramos que elas garantem a manutenção de um estado "natural", que sequestra alternativas de futuro, substituídas pela colonização de alternativas de escolha, o que impede a emancipação social e política.

Dessa forma, as produções científicas decorrentes de projetos de pesquisa em intervenção educacional são localizadas, na academia, pela linha de pesquisa adotada pelo pesquisador. "No desconhecimento do significado das questões inconscientes, que subjazem às práticas sociais, criaram-se escolas que lutam por um domínio político e que têm interferido na fragmentação do conhecimento produzido" (KIM, 2009, p. 28). Enquanto forma de resistência política, a concretude da intervenção educacional coloca o pesquisador em situação de desconhecimento e parte de uma ideia (preconcepção) para verificar como esta é percebida na realidade externa objetiva. Assim, a intervenção educacional desvela ideologias ocultas que garantem a manutenção de problemas que requeiram planejamentos de ação estratégica, interferindo na cultura em direção ao desejo dos sujeitos participantes, e se constitui como uma ciência aplicada na área socioeducacional. 
Os métodos utilizados nesta ciência são a pesquisa-ação e a pesquisa participante ${ }^{9}$. Por meio deles, a utopia passa de narração literária para incorporação na ação. Com eles, "o pesquisador adquire habilidade de entender que atributos da natureza foram construídos pela cultura (sistema de interpretação do mundo), para desvelar as práticas na busca de verdade (utopia). Assim, constrói-se a utopia de caminho" (KIM, 2009, p. 28).

A intervenção educacional possibilita inovação na ação concreta, que exige "uma consciência bastante aguda dos acasos, derivas e bifurcações, e nos impõe a reflexão sobre sua própria complexidade" (MORIN, 2015, p. 80). Podemos afirmar que esta técnica científica de pesquisa é essencial em situações de turbulência emocional decorrentes de situações de crise, que demandam soluções mais adequadas ao momento sociocultural, econômico e político em que vivemos, onde "milhões de seres sofrem o resultado dos efeitos do pensamento fragmentado e unidirecional" (MORIN, 2015, p. 83).

\subsection{A intervenção educacional e psicanálise: uma proposta possível}

A intervenção grupal tematizada com tempo limitado tem-se constituído como um espaço empírico de locução e interação que favorece a emergência do potencial criativo de sujeitos para a resolução de seus problemas (FLEURY; ABDO, 2005). A intervenção grupal de base psicanalítica articulada à técnica científica do psicodrama pedagógico é um modelo diversificado de prática educativa. Com ela, podem-se instituir novas relações entre o saber pedagógico e o científico, na medida em que ela possibilita a experimentação de alternativas de trabalho pedagógico, com reflexão crítica sobre sua utilização, interferindo na intersubjetividade dos sujeitos participantes. Neste tipo de intervenção, a dinamização de dispositivos de pesquisa-ação permite a apropriação de saberes coletivos, que podem ser utilizados no aprimoramento da inter-relação destes sujeitos com seus grupos de referência.

A intervenção nas áreas da Saúde e da Educação é mediada pelas instituições nas quais os sujeitos apresentam suas demandas explícitas e implícitas. A instituição escola fornece um campo para pesquisa propício para a promoção de um diálogo entre as observações derivadas de intervenções grupais e as condições de validade da teoria da técnica analítica. Os dispositivos de grupo podem ser considerados como uma "extensão" da psicanálise, com manejos clínicos mais adequados para atender às necessidades contemporâneas. Eles

\footnotetext{
${ }^{9}$ Pesquisa participante: para Brandão (1982, p. 10), constitui-se como um conhecimento coletivo, que a partir da intervenção recria o conhecimento de dentro para fora, permitindo ao usuário pensar, produzir e dirigir o uso de seu saber a respeito de si mesmo.
} 
permitem teorização, análise e abrem caminhos para novos aprendizados sobre o inconsciente. Segundo Anzieu (1993, p. 21-22):

[...] seu estudo traz indicações úteis para compreender, em um nível empírico, as ações que se desenvolvem em um grupo, assim como para agir no próprio grupo. [...] Mas o destino de um grupo depende igualmente das atitudes de outros grupos, do contexto social global, dos acontecimentos históricos locais ou gerais, vindo a funcionar depois como marcas ou referências.

Freud (1976a) considera as qualidades do sentir - teoria que fundamenta estudos das manifestações sensíveis do objeto e de suas formas de apreensão pelo sujeito em sua capacidade de estar com o outro - como agente histórico do conhecimento. Na atualidade, investigações científicas empreendidads por neo-freudianos (BION, 1966, 1987; CASTELO FILHO, 2015; KAUFFMANN, 2008; KIM, 2008; KIM; DIAS, 2017) partem do pressuposto segundo o qual:

Toda experiência emocional, origem do sujeito psíquico, baseia-se em uma vinculação do tipo estético entre sujeito e objeto, despojada de interesse, sem a finalidade de satisfazer pulsões ou formas de conhecimento e livre de julgamento determinante, sendo o sentimento de prazer da interação proveniente da contemplação reflexiva. (KAUFFMANN, 2008, p. 30)

Bion (1966) considera a importância desta vinculação do tipo estético entre o coordenador de grupo e os participantes. Para isto, o coordenador precisa manter-se sem desejo e sem memória (função revêrie), sem buscar significado imediato e linear da intersubjetividade presente no momento da sessão. Dessa forma, o coordenador prioriza a intuição e a empatia em vez da lógica do pensamento. Para isto, ele cria uma "cesura" (FREUD, 1976c, p. 138), uma barreira, uma repressão daquilo que não importa no momento presente e se concentra em pontos obscuros, que precisam ser organizados e armazenados na mente ${ }^{10}$, para depois serem compartilhados por meio da interpretação (BION, 1987, p. 126). Em outras palavras, "para a formação de conceitos é preciso que os objetos voltem a se integrar de acordo com as necessidades do $\operatorname{self}^{11}$, a fim de que o conhecimento seja genuíno e o aprendizado se dê a partir da experiência” (KAUFFMANN, 2008, p. 36). Só então o coordenador solicita o auxílio do juízo lógico, para captar a sublimidade do objeto "um passo adiante no caminho dos pensamentos puros, embriões de conceitos que se originam da própria interação" (KAUFFMANN, 2008, p. 32).

\footnotetext{
${ }^{10}$ Mente é uma dimensão ou fenomeno complexo que se associa ao pensamento, e que é denominada por Bion (1966) de "aparelho para pensar". A mente implica um conjunto de processos e atividades que se desenvolvem na psique de forma consciente e inconsciente e que, na sua maioria, são de caráter cognitivo, o que permite ao ser humano compilar informação, analisá-la e extrair conclusões, para resolver situações-problema no contexto socioeducacional.

11 "Neste sentido, o que está em minha mente não é mais a coisa-em-si, mas uma representação mental desta. As coisas tal como me parecem são os fenômenos, os objetos-em-si. O que minha subjetividade faz é transformar a coisa-em-si no objeto-em-si. [...] O objeto-em-si, que é uma representação do objeto externo, desperta em mim sentimentos de prazer e de desprazer. O objeto que percebo a partir destes sentimentos, e somente a partir deles, é o objeto estético." (KANT apud KAUFFMANN, 2008, p. 30, grifo nosso)
} 
Para Bion (1966), o juízo lógico desenvolve-se a partir das primeiras relações entre mãe e bebê. Ele depende do bom funcionamento da função alfa (condição de elaborar dados concretos/impressões sensoriais da experiência emocional em insights). Os dados concretos (elementos beta) relacionam-se a tudo o que é indesejado pelo bebê e por isso são expelidos/evacuados por meio das identificações projetivas ${ }^{12}$. A função alfa tem por objetivo integrar estes elementos dispersos para constituí-los como pensamentos oníricos da vigília (elementos alfa). Assim, eles são armazenados na mente e podem ser compartilhados por meio de linguagem adequada. Portanto, a linguagem está a serviço da representação daquilo que foi abstraído e armazenado na mente. Baptista (2013, p. 178), fundamentada em Heidegger, supõe que apenas o acesso à "linguagem própria e daquilo que ela oculta como o ainda não pensado, o ainda-a-vir, pode permitir a recuperação desse tempo que, ociosamente, deixa vir até si a verdade".

Bion (1966) considera o pensador como o sujeito capaz de pensar o próprio pensamento. Segundo Castelo Filho (2015), apesar dos diferentes modos de anular ou esvaziar o caráter revolucionário, alguns grupos organizam-se para a entrada do líderpensador, aquele que traz evolução ao grupo. No entanto, os campos e os estados mentais envolvidos permitirão maior ou menor processo de elaboração na produção criativa, devido à resistência à mudança, pelo medo do vazio provocado pela quebra de padrões culturais e consequente capacidade de pensar.

\section{Projetos de pesquisa em intervenção educacional}

O campo da ação nos impõe a necessidade de pensamento estratégico e consciência das derivas e transformações, pois "a ação é estratégica" (MORIN, 2015, p. 79).

Em nossa opinião, a metodologia psicodramática criada por Moreno (1993) é adequada em intervenções educacionais porque permite "apreender e catalisar em ação e interação as tensões latentes in vivo em sua especificidade e particularidades próprias" (NAFFAH NETO, 1979, p. 133), mas sua produção imaginária deveria facilitar o esforço de racionalidade autocrítica na construção do conhecimento. Por esse motivo, propusemos um método de intervenção sociopsicodramática, que articula o psicodrama pedagógico com o pensar psicanalítico. Por meio de aprendizagem cooperativa, a descentralização do

\footnotetext{
${ }^{12}$ Identificação projetiva: termo criado originalmente por Klein (1991). Neste artigo, é considerada como fantasia inconsciente que se manifesta por um mecanismo de defesa, no qual aspectos internos do professor são negados e atribuídos aos alunos (objeto externo).
} 
conhecimento obtido em sua produção possibilita a criação de redes autossustentáveis, que incluem a inovação.

Essa proposta pode constituir-se como uma forma de resistência política, porque a educação informal inclusiva permite a emancipação do cidadão, quando se "reelabora a noção e a prática da aprendizagem em seu sentido de reconstrução política" (FLEURY; MARRA, 2008, p. 14).

A seguir, temos a síntese de alguns projetos de intervenção educacional. As abordagens e os instrumentos metodológicos utilizados obedeceram aos procedimentos éticos estabelecidos para a pesquisa científica em Ciências Humanas, por envolverem sujeitos humanos. Com a apresentação destes projetos, objetivamos exemplificar possibilidades de aplicação do psicodrama como instrumento de pesquisa-ação.

\subsection{Racionalizando o uso da água: programa educacional construído a partir da visão da população da cidade de São Paulo sobre essa problemática}

Saneamento Básico do Estado de São Paulo (Sabesp) e a Federação Brasileira de Psicodrama (Febrap), com acordo de trabalho com a Fundação de Apoio à Universidade de São Paulo (Fusp) e o Laboratório de Psicologia Socioambiental (Lapsi) do Departamento de Psicologia Social do Instituto de Psicologia da USP. Apesar de ter sido aprovado em todas as instâncias, ele foi desativado após aguardarmos verbas estaduais até 2002. Consideramos, no entanto, este modelo de projeto como um exemplo possível de aplicação do psicodrama na ação pedagógica, para instrumentalizar uma educação ambiental voltada para programas com a participação da sociedade civil e do Estado, tais como o do uso racional da água. Por meio dele, esperávamos influenciar na construção de um futuro desejável, como estratégia de ação política ampliada em redes de comunicação. O objetivo era evitar que a questão da falta evoluísse para a escassez da água, construindo um mapeamento de diferentes percepções que projetariam opiniões sobre a problemática, em sua heterogeneidade.

Esta intervenção educacional seria realizada em duas fases. Na primeira, criaríamos um modelo emancipatório e na segunda, este modelo seria disparado por meio de emuladores culturais, em redes autossustentáveis abertas para o futuro e para o exterior social.

A primeira fase seria subdividida em quatro etapas: 
1) definição da estrutura do projeto (concepção e detalhamento) e de suas condições de implementação (treinamento dos psicodramatistas participantes e definição dos centros propulsores - amostra da população, na base cartográfica e pelos dados fornecidos por líderes da Sabesp);

2) construção da carta de ação única por subgrupos da amostra, que seria categorizada por representantes de todos os grupos participantes;

3) divulgação da carta de ação produzida para toda a população da cidade e do estado de São Paulo, pelos meios de comunicação de massa;

4) avaliação incremental articulada do planejamento, visando a adequações contínuas das decisões do projeto.

$\mathrm{Na}$ segunda fase, a rede de disparadores (cem psicodramatistas da primeira fase) garantiria o conhecimento do método nas escolas de formação de psicodramatistas filiadas à Febrap, para sua aplicação ao máximo possível de cidadãos da população brasileira. Em outras palavras, o projeto constituiria agentes engajados no processo de conscientização e de implementação de ações a ele pertinentes, relativos ao uso racional da água.

\subsection{Projetos de intervenção educacional com professores na inter-relação com os alunos e resolução da tarefa pedagógica}

O projeto de intervenção educacional aqui sintetizado (KIM; DIAS, 2017) decorre de investigação de pós-doutorado realizada no ano de 2017. O objetivo foi verificar o efeito da intervenção na instalação de um "grupo técnico de trabalho" (BION, 1969) centrado na tarefa de ensinar e aprender leitura e escrita em sala de aula.Trata-se de uma investigação psicanalítica sobre as políticas públicas educacionais aplicadas no ambiente cultural, na qual analisamos como o fenômeno da transferência ${ }^{13}$ perpassa as relações de poder estabelecidas entre diferentes atores que se inter-relacionam em um agrupamento de um distrito de Portugal e em um bairro da zona oeste da cidade de São Paulo. A pesquisa retomou estudo (KIM, 2008) no qual se detectou que questões da história pessoal de professores eram atualizadas na inter-relação com os alunos em sala de aula e que, quando esses professores compreendiam o significado dessa atualização em intervenções individuais (fora do ambiente escolar), havia uma mudança em sala de aula, que resultava numa melhor resolução da tarefa pedagógica.

\footnotetext{
${ }^{13}$ Transferência: termo criado originalmente por Freud (1976b) e adaptado por Kim (2008, p. 33): "é um estado de turbulência emocional que afeta a percepção do professor", "interfere na construção do conhecimento subjetivo" (SIMON, 1991, p. 22) e "obstrui a tarefa pedagógica" (BION, 1969). A intervenção grupal pode revertê-lo em um instrumento de empatia e intuição (SIMON, 1991, p. 22), para que o professor deixe de ocupar o lugar que o grupo de alunos projeta nele e concentrar-se na tarefa de ensinar (KIM, 2017, p. 3).
} 
O presente estudo se propôs a replicar o anteriormente citado, por meio de uma estratégia de intervenção grupal com professores de $1^{\circ}$ ano do ensino básico, distribuídos em dois grupos: um no Brasil e outro em Portugal. Ele se desenvolveu em duas fases, sendo que na primeira foi feita a identificação dos sujeitos (recrutamento e seleção de professores em escolas parceiras) e na segunda fase foi realizada a coleta de dados, por meio de uma intervenção tematizada grupal breve. A segunda fase ocorreu apenas com os professores brasileiros, porque foi interrompida pela direção geral do agrupamento antes de ser iniciada com os professores portugueses.

$\mathrm{Na}$ primeira fase utilizou-se como instrumento de pesquisa a entrevista profunda em prevenção (SIMON, 2005) e a técnica científica do psicodrama pedagógico Apresentação do Átomo Social ${ }^{14}$, pensada pelo método psicanalítico (KIM, 2008). Sua análise indicou que o fenômeno da transferência disparado na Apresentação do Átomo Social favoreceu a associação de cenas dos personagens representados, a qual era equivalente à associação de ideias em psicanálise; e, ainda, que a interpretação realizada sob a forma da técnica psicodramática de duplo possibilitou o desejo de um processo criativo para se pensar. Isto se evidenciou pelo controle do impulso agressivo inconsciente frente à frustração atualizada durante a aplicação do instrumento, permitindo, assim, um tempo de preparação para o ócio, como condição para se pensar o próprio pensamento, com o apoio da pesquisadora.

Este fato foi muito facilitador para o desenvolvimento da segunda fase com os professores brasileiros. Já os sujeitos-professores portugueses ficaram na falta do que "não tinham" (intervenção grupal), porque fora projetado no outro: a pesquisadora. Mas, é na ausência que se pode visualizar o "seio ansiado" para reconhecê-lo como a imagem de algo que está realmente ausente (condição necessária para a simbolização). Portanto, os campos e estados mentais envolvidos na investigação em Portugal não permitiram uma elaboração na produção criativa coletiva, nas questões pessoais que estavam interferindo na resolução da tarefa pedagógica de ensinar e aprender a leitura e escrita.

A segunda fase da investigação educacional, realizada apenas com os professores brasileiros em quatro encontros grupais de periodicidade semanal, teve como foco a angústia de separação (queixa comum dos sujeitos participantes) e a capacidade de simbolização. Os dados obtidos, sua análise e compreensão interpretativa esclareceram a importância do

\footnotetext{
${ }^{14}$ Apresentação do Átomo Social: solicitamos ao professor que representasse, por meio de objetos intermediários (objetos da sala), as "pessoas significativas", aquelas que interferiram positivamente ou negativamente em sua vida profissional. Supõe-se que as relações estabelecidas entre estas pessoas-personagens no mundo interno do sujeito possam estar sendo representadas simbolicamente pela disposição destes objetos intermediários. Em seguida, o professor representou dramaticamente os objetos (personagens mais significativos) para pesquisa de aprofundamento em seu mundo interno e para tornar possível o insight de sua influência na relação entre o professor e a turma de alunos na sala de aula, na atualidade.
} 
momento presente para que o Ego dos sujeitos adquirisse mais capacidade de suportar a tensão, conter a ação impulsiva e sentir a falta de gratificação. Desse modo, as professoras participantes puderam refletir sobre ideias preconcebidas, referentes à aprendizagem da leitura e escrita em sala de aula, o que possibilitou a realização de ações diferenciadas e melhor desempenho da turma de alunos nesta competência.

Esta intervenção educacional indicou também as intenções da instituição escolar, historicamente determinadas por padrões alicerçados na cultura, enquanto extensões do próprio Ego social. A ostentação da autoridade aceita e justificada pela tradição personificouse na figura da coordenação geral (Portugal) e nos coordenadores pedagógicos (Brasil). A autonomia dos coordenadores pedagógicos de cada escola parceira possibilitou a realização da segunda fase da pesquisa com os professores brasileiros.

O trabalho com as cenas dramáticas que representavam cenas cotidianas da instituição escolar permitiu compreender questões inconscientes que subjaziam à inter-relação professor e alunos, em sala de aula. Assim, os professores brasileiros começaram a modificar suas atitudes frente às condutas inadequadas de alunos, na medida em que aprenderam a suportar a frustração e o sentimento de solidão.

Nas entrevistas individuais, ocorridas cinco meses após a intervenção grupal sem qualquer contato com a pesquisadora, os professores mostraram o quanto este procedimento possibilitou sua autonomia frente ao outro emocionalmente significativo, discernimento para fazer escolhas, inibição de impulsos agressivos frente a cenas frustrantes do cotidiano escolar e da vida pessoal, bem como assumiram maior responsabilidade sobre os próprios atos na relação com os alunos. Esta evolução interferiu na melhor resolução da tarefa pedagógica, tanto no encerramento com a turma de alunos de 2017 como na escolha e postura dos sujeitos frente às novas turmas de alunos em 2018.

Portanto, pudemos verificar que a falta de espaços de locução no ambiente escolar interfere na potencial condição de aguentar a frustração para se pensar com autonomia. Mantém-se, assim, a precariedade do corpo docente atravessado pelas formas naturalizadas de poder, que continuará sendo escoada no setor orgânico até que surjam líderes "pensadores", que enfrentem o poder disciplinar local, na forma de resistência política. 


\subsection{Projetos de intervenção educacional com idosos}

O projeto de intervenção educacional abaixo sintetizado (KIM, 2016, 2017) teve como objetivo analisar o lugar do envelhecimento na contemporaneidade. Considerou-se o ócio como eixo estruturador para a recuperação do tempo, que, por meio de linguagem adequada interpretação psicanalítica -, favorece o lugar do "não pensado" e amplia a percepção dos idosos participantes. Em nove encontros quinzenais, trabalhou-se o sentimento de exclusão na terceira idade, apresentado como situação-problema central que interfere na produtividade e em problemas orgânicos. A interpretação feita pela pesquisadora ajudava os sujeitos a pensar sobre o que estava por detrás da pulsão de morte (padrões repetitivos de respostas inadequadas) e de seu desejo de vida (respostas inovadas). Com ela, os sujeitos puderam reorganizar suas respostas de forma mais adequada. Seus projetos existenciais ganharam forma no contexto dramático e mais consistência, na medida em que foram testados no contexto sociocultural.

\subsection{Intervenções educacionais pontuais}

A síntese da intervenção educacional realizada em uma sala de aula com 15 doutorandos de um departamento de uma universidade portuguesa objetiva exemplificar como a interdisciplinaridade ${ }^{15}$ em duas disciplinas pode constituir-se como transdisciplinaridade ${ }^{16}$.

Inicialmente, realizamos a integração dos alunos participantes presentes, por meio da técnica de apresentação da "origem do próprio nome", o que facilitou o fortalecimento de vínculos necessários à próxima etapa: a inversão de identidade com o doutorando sentado na cadeira ao lado. Desse modo, enquanto personagem-colega, cada participante levantou suposições sobre as expectativas daquele encontro para o personagem que ali representava, as quais puderam ser confirmadas ou não pelo próprio sujeito no momento seguinte.

O aquecimento específico dos conteúdos a serem trabalhados foi realizado por meio da “técnica das papeletas". Cada doutorando deveria associar quatro palavras (escrever uma em cada papeleta) que representavam as disciplinas a serem integradas. Em seguida, as 60 papeletas foram selecionadas e organizadas em um grande quebra-cabeça, que representava o pensamento concreto grupal. Neste processo, os participantes puderam gradativamente se constituir como sujeitos ativos do conhecimento tendo, como produto parcial, uma imagem

\footnotetext{
${ }^{15}$ Interdisciplinaridade é a justaposição de duas ou mais disciplinas, situadas geralmente no mesmo nível hierárquico e agrupadas de modo a fazer aparecer as relações existentes entre elas.

${ }^{16}$ Transdisciplinaridade é uma abordagem científica que visa à unidade do conhecimento.
} 
tridimensional co-construída por todos eles. Em seu desenvolvimento, por meio de nossa interpretação, eles puderam conscientizar-se, na ação, de padrões de convivência ali atualizados na transferência, que desvelavam as relações de poder que permeavam a interrelação professor-alunos naquela universidade. As palavras mais significativas para o grupo foram organizadas em subgrupos de participantes, que escolheram democraticamente seus representantes, os quais utilizaram o próprio corpo na construção de uma "escultura viva", cujos personagens-palavras simbolizaram o conhecimento construído de forma coletiva pelo grupo.

Ao compartilharem suas impressões sensoriais e experiências emocionais, este conhecimento grupal foi-se organizando na forma do "pensar o próprio pensamento" de forma abstrata e consciente, por meio de linguagem integrativa, que denunciou aspectos do colonialismo cultural e o desejo de reflexão de questões ideológicas que o permeavam. A intervenção educacional foi encerrada com um grande abraço grupal, embalado por sons que integravam melodias dos diferentes países de origem dos participantes e em que, de forma harmônica, os participantes puderam olhar-se amorosamente através do olhar do outro.

\section{Considerações finais}

Sem conclusões ou receitas, quisemos adentrar neste artigo as contradições pertinentes ao campo científico e reivindicar a ação política engendrada pelas intervenções educacionais.

Estamos cientes de que a síntese teórica e prática aqui apresentada é precária frente à luta contra a insignificância e o mal-estar contemporâneo da cultura, que, sob forma destrutiva, alastra-se por todos os continentes. No entanto, gostaríamos de realçar a força da intervenção educacional na construção de vias regeneradoras que reorganizem o pensamento, a educação e a cultura de humanidade, para evitar a autodestruição do ser humano neste planeta. 


\section{Referências}

ANZIEU, D. O grupo e o inconsciente: o imaginário grupal. São Paulo: Casa do Psicólogo, 1993.

ANZIEU, D.; MARTIN, J. Y. La dinâmica de los grupos pequeños. Buenos Aires: Kapelusz, 1992.

BAPTISTA, M. M. Ócio, temporalidade e existência: uma leitura à luz da fenomenologia e hermenêutica heideggereanas. Revista Lusófona de Estudos Culturais, Braga, v. 1, n. 2, p. 173-182, 2013.

BAPTISTA, M. M. Ócio. A questão do Outro na Europa da cultura. In: CUNHA, N. (Coord.). Europa: globalização e multiculturalismo: actas dos Encontros de Outono, 19-20 nov. 2004. Vila Nova de Famalicão: Câmara Municipal: Ausência: Museu Bernardino Machado, 2006. p. 165-179.

BION, W. R. Dinâmica de grupo: uma revisão. In: KLEIN, M.; HEIMANN, P.; KIRLE, R. E. (Org.). Temas de psicanálise aplicada. Rio de Janeiro: Zahar, 1969. p. 166-206.

BION, W. R.Os elementos da psicanálise (inclui o aprender com a experiência). Rio de Janeiro: Zahar, 1966.

BION, W. R. Tradução: duas conferências de W. R. Bion. Turbulência emocional. Revista Brasileira de Psicanálise, São Paulo, v. 21, n. 121, p. 121-133, 1987.

BRANDÃO, C. R. Pesquisa participante. São Paulo: Brasiliense, 1982.

CABEZA, M. C; AMIGO, M. C. O encontro entre o ócio e a cultura: reflexões sobre o ócio criativo desde a investigação empírica. In: BAPITSTA, M. M.; VENTURA, A. (Org.). Do ócio: debates no contexto cultural contemporâneo. Coimbra: Grácio, 2014. p. 11-32.

CASTELO FILHO, C. O processo criativo: transformação e ruptura. São Paulo: Blucher, 2015.

FLEURY, H. J.; ABDO, C. H. N. Uma proposta psicoterápica para a mulher climatérica. In: FLEURY, H. J. (Org.). Intervenções grupais na saúde. São Paulo: Ágora, 2005. p. 52-71.

FLEURY, H. J.; MARRA, M. M. Introdução. In: MARRA, M. M. (org.). Grupos: intervenção socioeducativa e método sociodramático. São Paulo: Ágora, 2008. p. 13-21.

FREUD, S. O estranho. In: FREUD, S. Obras psicológicas completas de Sigmund Freud. Edição standard brasileira. Comentários e notas de James Strachey. Rio de Janeiro: Imago, 1976a. v. 18, p. 13. 
FREUD, S. Fragmentos da análise de um caso de histeria. In: FREUD, S. Obras psicológicas completas de Sigmund Freud. Edição standard brasileira. Comentários e notas de James Strachey. Rio de Janeiro: Imago, 1976b. v. 7, p. 113.

FREUD, S. Inibições, sintomas e ansiedade. In: FREUD, S. Obras psicológicas completas de Sigmund Freud. Edição standard brasileira. Comentários e notas de James Strachey. Rio de Janeiro: Imago, 1976c. v. 20, p. 107-180.

FOUCAULT, M. Nietzche, a genealogia e a história. In: FOUCAULT, M. Microfísica do poder. Organização, introdução e revisão técnica de Roberto Machado. Rio de Janeiro: Graal, 1979. p. 12-23.

HABERMAS, J. Tecnologia e ciência como “ideologia”. Lisboa: Edições 70, 1994.

KAUFFMANN, A. L. Sobre a contemplação reflexiva estética na sessão psicanalítica. Revista Brasileira de Psicanálise, São Paulo, v. 42, n. 4, p. 29-39, 2008.

KIM, L. M. V. Estudo da contratransferência do professor na inter-relação com o grupo de alunos. 2008. Tese (Doutorado em Psicologia Clínica) - Instituto de Psicologia, Universidade de São Paulo, São Paulo, 2008.

KIM, L. M. V. Intervenção sociopsicodramática: forma particular de exercício do poder político. Revista Brasileira de Psicodrama, São Paulo, v. 21, n. 1, p. 25-38, 2013.

KIM, L. M. V. Pensamento e relações amorosas: uma experiência com grupo de idosas. In: FREITAS, D. C. (Org.). Por trás dos fatos: a psicanálise pode explicar! São Paulo: Vetor, 2017. p. 22- 40.

KIM, L. M. V. Psicodrama e intervenção social. Revista Brasileira de Psicodrama, São Paulo, v. 17, n. 2, p. 25-32, 2009.

KIM, L. M. V. Tempo do ócio: espaço do pensamento para a construção da espontaneidade, em uma intervenção grupal com idosas. Revista Brasileira de Psicodrama, São Paulo, v. 24, n. 1, p. 76-82, 2016.

KIM, L. M. V.; DIAS, E. T. M. Angústia de separação e capacidade de simbolizar na interrelação entre o professor e a turma de alunos. In: KIM, L. M. V.; BAPTISTA, M. M.; DIAS, E. T. M. (Org.). Polifonias psicológicas e educacionais: olhares direcionados para a escola e a cultura. São Paulo: Paidos, 2017. No prelo. ISBN 978-85-462-1100-5.

KLEIN, M. Notas sobre alguns mecanismos esquizóides. In: KLEIN, M. Inveja e gratidão e outros trabalhos. Rio de Janeiro: Imago, 1991. p. 17-43.

MORENO, J. L. Psicodrama. São Paulo: Cultrix, 1993.

MORIN, E. Educação e complexidade: os sete saberes e outros ensaios. Organização de M. da C. Almeida e E. de A. Carvalho. 4. ed. São Paulo: Cortez, 2003. 
MORIN, E. Introdução ao pensamento complexo. Tradução de E. Lisboa. 5. ed. Porto Alegre: Sulina, 2015.

MORIN, E. O paradigma perdido: a natureza humana. Sintra: Europa-América, 1973.

NAFFAH NETO, A. Psicodrama: descolonizando o imaginário. São Paulo: Brasiliense, 1979.

RIBEIRO, R. W. Paisagem cultural e patrimônio. Rio de Janeiro: Iphan: Copedoc, 2007.

SANTOS, M. Pensando o espaço do homem. 5. ed. São Paulo: Edusp, 2004.

SEVERINO, A. J. Conhecimento, subjetividade e ideologia. Educação e Subjetividade, São Paulo, ano 1, n. 1, p. 11-36, 2005.

SIMON, R. Impotência contratransferencial: esboço de compreensão metapsicológica. Revista Brasileira de Psicanálise, São Paulo, v. 26, n. 1-2, p. 15-26, 1991.

SIMON, R. Psicoterapia breve operacionalizada. São Paulo: Casa do Psicólogo, 2005.

TASSARA, E. T. de O. Análise de um programa de intervenção sobre o sistema educacional: da premissa à possibilidade. 1982. Tese (Doutorado em Psicologia Clínica) - Instituto de Psicologia, Universidade de São Paulo, São Paulo, 1982. 